\title{
Prevalence of enterotoxemia and antibiogram of Clostridium perfringens isolated from diarrheic goat in the vicinity of district Tharparkar, Sindh, Pakistan
}

\author{
Muhammad Mohsen Rahimoon ${ }^{1}$, Jam Kashif Zaman², Asma Babar ${ }^{3 *}$, \\ Amjad Hussain Mirani ${ }^{2}$ and Nazeer Hussain Kalhoro ${ }^{4}$ \\ 1. Department of Animal Reproduction, Shaheed Benazir Bhutto University of Veterinary \& Animal Sciences, \\ Sakrand-Pakistan \\ 2. Department of Veterinary Medicine, Sindh Agriculture University Tandojam-Pakistan \\ 3. Faculty of V\&AS, Lasbela University of Agriculture, Water and Marine sciences, Uthal 90150, Balochistan- \\ Pakistan \\ 4. Sindh Institute of Animal Health Karachi-Pakistan \\ *Corresponding author's email: asmababar53@yahoo.com
}

Citation

Muhammad Mohsen Rahimoon, Jam Kashif Zaman, Asma Babar, Amjad Hussain Mirani and Nazeer Hussain Kalhoro. Prevalence of enterotoxemia and antibiogram of Clostridium perfringens isolated from diarrheic goat in the vicinity of district Tharparkar, Sindh, Pakistan. Pure and Applied Biology. Vol. 10, Issue 2, pp408-415. http://dx.doi.org/10.19045/bspab.2021.100044

Received: 01/07/2020 Revised: 26/09/2020

Accepted: 01/10/2020

Online First: 08/10/2020

\section{Abstract}

Goat is amongst the earliest small ruminant species to be domesticated and have been reared for meat and milk purpose. Enterotoxemia is a bacterial disease, also said to be pulpy kidney disease or over-eating disease, occurs in sheep and goat throughout the world. In Caprine this disease is caused by a bacteria called Clostridium perfringens type D, which is a gram positive, spore forming, anaerobic, and rod shaped. 100 faecal samples were obtained from diarrheic goats from four Taluka of District Tharparker Sindh, Pakistan. These samples were collected aseptically in ultra violet treated contamination free polyethylene bags which were contained double volume of phosphate buffer saline (PBS) and samples were brought to the laboratory (Sindh Poultry Vaccine Centre Korangi, Karachi, Sindh, Pakistan), in portable cooler containing an ice pack, then samples were refrigerated at $4 \mathrm{C}$ until being processed. A chain of laboratory techniques, including colony characteristics, biochemical analysis, gram staining and growth on Robertson cooked meat (RCM) media was performed. Furthermore, all positive samples were subjected to check their antibiogram through 2-fold Micro Broth Dilution Method by using Minimum Inhibitory Concentration (MIC) method. Among 100 diarrheic samples the percentage of positive cases was $(44.44 \%)$ in Talulka Dahali followed by Chachro (26.67\%), Islamkot (17.78\%) and Mithi (11.11\%). Among 45 samples, a total of 01 sample was shown their resistant at the concentration of $16 \mu \mathrm{g} / \mathrm{ml}$ against Amoxicillin. Although for Chloramphenicol, a total of 01 sample was shown their resistant at the concentration of $16 \mu \mathrm{g} / \mathrm{ml}$ and 01 samples was shown their resistant at $32 \mu \mathrm{g} / \mathrm{ml}$ concentration. Furthermore, there was no any sample show its resistant at the different concentration of Trimethoprim/Sulphamethaxzol used in this study. 
Keywords: Antibiogram; Antibiotic; Clostridium perfringens; Enterotoxemia; Prevalence

\section{Introduction}

Goat is amongst the earliest small ruminant species to be domesticated and have been reared for meat and milk purpose, since 2500 B.C. in the Middle East [1]. At present there are $>300$ breeds of goats are found in different areas of the world [2]. It has been observed that maximum production can be obtained by protecting them from different prevalent diseases like enterotoxemia [3]. Enterotoxemia is a bacterial disease, also said to be pulpy kidney disease or overeating disease, occurs in sheep and goat throughout the world characterized by diarrhoea and dysentery, mostly occurs in animals which are supplying with well feed [4]. In Caprine this disease is caused by a bacteria called $C$. perfringens type $\mathrm{D}$, which is a gram positive, spore forming, anaerobic, and rod shaped [5]. $C$. perfringens, a rapid-growing pathogen known to secrete an arsenal of $>20$ virulent toxins [6], and at the start of monsoon season, frequent disease outbreak of enterotoxaemia in sheep and goat have been encountered every year in Pakistan by $C$. perfringens Type D [7]. Almost all types of $C$. perfringens have produced alpha and epsilon toxin, $C$. perfringens type $\mathrm{D}$ also produce these toxins to develop enterotoxaemia in goat and sheep [8]. Factors which are responsible for exposing the animal towards the enterotoxaemia are stress, over feeding and high parasitic load in the intestine, it will create the disturbance in microorganisms which are present in the intestine $[9,10]$.

Antibiotics are the chemical substances which are used to stop the growth or to kill the microbes [11], as some of the chemotherapeutic agents are bacteriostatic and some are bactericidal. Antibiotics are specific for specific microorganisms such as antimycotics, antibacterial, antiprotozoal and antiparastic, it will make the antibiotics to be different from disinfectants or other antimicrobials [12]. The ability of microorganisms to grow even in the presence of chemotherapeutic agents create a disturbance in treating various infectious diseases in animals as well as in human being [13]. Therefore, it is very much necessary to reduce the problem of drug resistant against multiple microorganisms by applying some preventive measures like to understand the mode of action of various drugs against different microbes, proper use of antibiotics and by avoiding selfmedication, hence the present study is designed to determine the effect of various antibiotics against the isolates.

\section{Materials and Methods}

Sample Collection and Isolation of Clostridium perfringens Sample collection

All faecal samples were collected from diarrhoeic goats in district Tharparkar, Sindh, Pakistan. The clinically ill goats were selected in this study and samples were collected from different Veterinary clinics and in the vicinity of district Tharparkar.

A total of 100 faecal samples were collected from diarrhoeic goats, The samples were collected aseptically in Ultra Violet (UV) treated contamination free polyethylene sachets which were contain double volume of phosphate buffer saline (PBS) and samples were brought to the laboratory Sindh Poultry Vaccine centre Korangi Karachi, in portable cooler containing an ice pack and then samples were refrigerated at $4^{\circ} \mathrm{C}$ until being processed within $48 \mathrm{hr}$ of collection for isolation and identification of $C$. Perfringens by chain of laboratory technique including colony characteristics, gram staining, biochemical tests and growth on Robertson cooked meat (RCM) media.

\section{Isolation and identification}

All the fecal samples were inoculated into (RCMB). The inoculated RCMB tubes were placed in water bath for a period of 10-15 mins at $80^{\circ} \mathrm{C}$ to remove the nonspore forming aerobic bacteria. Finally, the 
RCMB tubes were incubated in anaerobic jar at $37^{\circ} \mathrm{C}$ for 24 to 48 hours, then for sub culturing with the help of sterilized wire loop, picked up the bacterial colonies from (RCMB) tubes and has streaked on prepared RCM agar medium in petri dishes, then petri dishes were placed in incubator at $37^{\circ} \mathrm{C}$ for 24 hours, the processing of sub culturing continue until the pure growth was observed.

\section{Antimicrobial susceptibility test}

The Minimum inhibitory concentration of bacterial isolates was done in Sindh Poultry Vaccine Centre Korangi Karachi, Pakistan. The antibiogram of $C$. perfringens isolates were determined through Minimum inhibitory concentration test by using (Micro broth 2-fold dilution method) on Muller Hinton (MH) agar (Oxide, UK) and 1:1000 dilution was prepared for minimum inhibitory concentration (MIC) test for that $6 \mu \mathrm{l}$ of bacterial culture of Clperfringens in RCM broth were added into $6 \mathrm{ml}$ of Muller Hinton broth.

96 well plates of micro titer plates were used for MIC test. Two wells of micro titer tray were used for positive and negative control. Well number 11 of the micro titer tray was used as positive control, having the bacterial culture and media. Well number 12 was used as a negative control, have only contains the media. The wells' optical density values were recorded by enzyme-linked immunosorbent assay (ELISA) reader at $524 \mathrm{~nm}$. After 24 hours of incubation at $37^{\circ} \mathrm{C}$, the optical density values again recorded. The lowest concentration showed that inhibition of growth by decrease in optical density (OD) value was considered to be minimum inhibitory concentration of antibiotic against test organisms. A concentration $1280 \mu \mathrm{g} / \mathrm{ml}$ of Amoxicillin, $1270 \mu \mathrm{g} / \mathrm{ml}$ of chloramphenicol and $1260 \mu \mathrm{g} / \mathrm{ml}$ of Trimethoprim/sulphamethaxzole (Sigma, USA) was used for MIC against $C$. perfringens.

$C$. perfringens isolates culture were added in each well of micro titer tray. In first well
$180 \mu 1$ of culture was added and in remaining all wells $100 \mu \mathrm{l}$ of bacterial culture was added. Then $20 \mu \mathrm{l}$ of Amoxicillin (Sigma, USA) were added in first well and mixed by push up of Eppendorf tube. After that $100 \mu 1$ of culture should be introduced from first well to next and repeat till last well. The final subculture of bacterial Isolates was discarded. Then MIC plates were placed in incubator at $37^{\circ} \mathrm{C}$ for 24 hours. Results of MIC test have been obtained by performing it $3 \mathrm{X}$.

Same procedures were applied for chloramphenicol and Trimethoprim/ sulphamethaxzole in order to determine their minimum inhibitory concentration against $C$. perfringens isolates.

\section{Statistical analysis}

The data obtained was proceeded for statistical procedure as summary stat to observed the descriptive measures by using computerized statistical package i.e. Student Edition of Statistics (SXW), version 8.1 (copyright 2005, Analytical software, USA).

\section{Results}

\section{Percentage prevalence of} enterotoxaemia among diarrhoeic goats on taluka basis district Tharparkar, Sindh, Pakistan

Total 100 diarrhoeal samples were collected from goats. All samples were cultured on different media to isolate the pure colony of $C$. perfringens then pure culture of organism was confirmed through grams staining and by biochemical properties. 45 samples were found positive with $C$. perfringens in diarrhoeal goats, while 55 samples were found negative out of 100 samples. Results have indicated that Dahali was highly infected with enterotoxaemia amongst four Taluka of district Tharparkar. These results shows that highest percentage $(44.44 \%)$ found in Dahali Talulka followed by Chachro (26.67\%), Islamkot (17.78\%) and Mithi $(11.11 \%)$ respectively as shown in (Table $1)$. 
Morphological characteristics of $C$. perfringens isolated from diarrhoeic goats in the vicinity of district Tharparkar

Morphologically identified sample were subjected to different biochemical tests to confirm the bacterial strains of $C$. perfringens before (MIC). The $C$. perfringens were recorded positive for methyl red, gelatin liquefaction and triple sugar iron test $C$. perfringens was found negative for catalase, oxidase, urease, indole, and Voges-Proskauer test. It has been showed A/A properties on triple sugar iron medium, this isolates showing the property of acidic slant and acidic but indicate that the sugar present in the media was fermented (Fig. 1; Table 2).

Table 1. Percentage prevalence of Enterotoxaemia among diarrhoeic goats in the four Taluka of district Tharparkar

\begin{tabular}{|c|c|c|}
\hline Taluka & No. of Positive samples & Percentage \\
\hline Chachro & 12 & $26.67 \%$ \\
\hline Dahali & 20 & $44.44 \%$ \\
\hline Islamkot & 08 & $17.78 \%$ \\
\hline Mithi & 05 & $11.11 \%$ \\
\hline
\end{tabular}

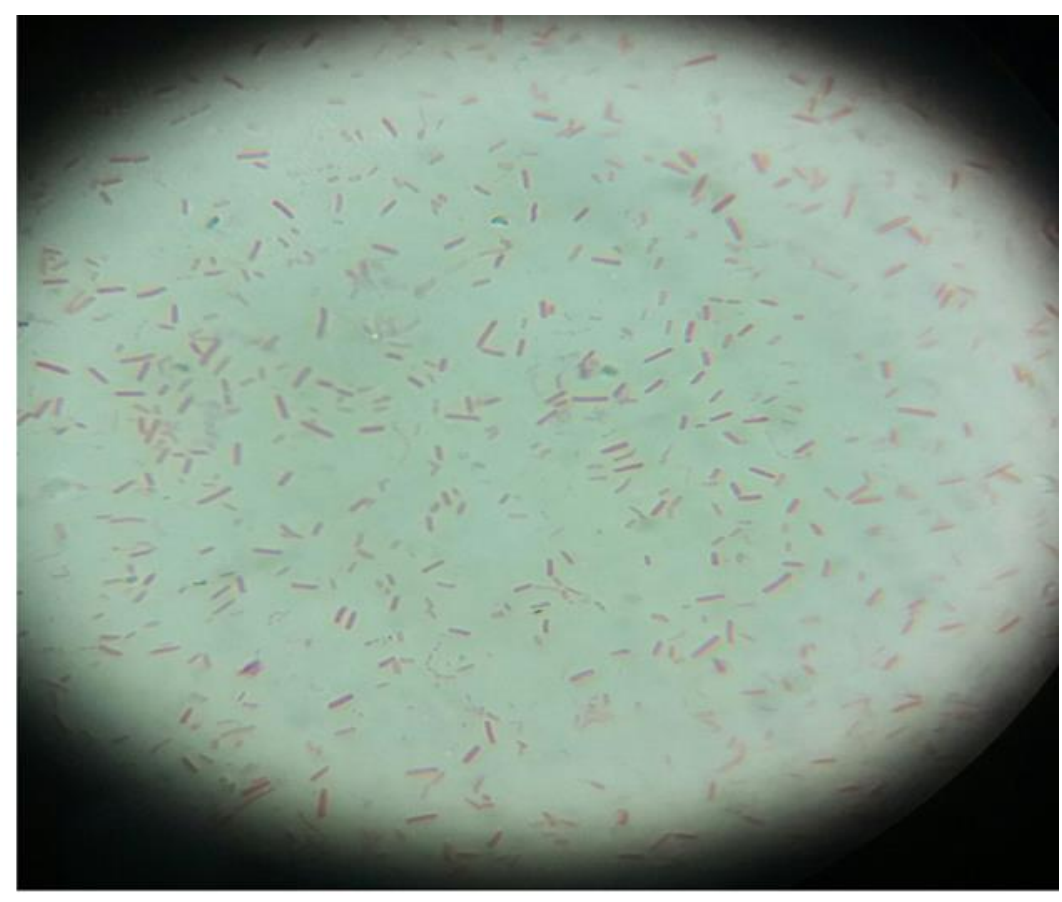

Figure 1. Biochemical characteristics of Clostridium perfringens isolates

Table 2. Biochemical characteristics of clostridium perfringens isolated from diarrhoeic goats in the vicinity of district Tharparkar

\begin{tabular}{|c|c|c|c|c|c|c|c|c|c|}
\hline $\begin{array}{c}\boldsymbol{C} . \\
\text { perfrigens }\end{array}$ & Leci. & M.R & GLT & TSI & Cat. & Oxid & Ure & Ind & V.P \\
\hline & $+\mathrm{ve}$ & $+\mathrm{ve}$ & $+\mathrm{ve}$ & A/A & $-\mathrm{ve}$ & $-\mathrm{ve}$ & $-\mathrm{ve}$ & $-\mathrm{ve}$ & $-\mathrm{ve}$ \\
\hline
\end{tabular}

Leci; Lecithinase, M.R; Methyl Red, GLT; Gelatin Liquefaction Test, TSI; Triple Sugar Iron, Cat.; Catalase, Oxid.; Oxidase, Ure; Urease, Ind; Indole, V.P; Voges proskauer, 
Minimum Inhibitory Concentration (MIC; $\mu \mathrm{g} / \mathrm{ml}$ ) sensitivity and resistant of selected antibiotics against Clostridium perfringens isolates from diarrheic goat

In order to detect the prevalence of Enterotoxaemia among goats in district Tharparkar, fecal sample were collected in the vicinity of district Tharparkar from diarrhoeal goats and were brought to Sindh poultry Vaccine Centre Korangi Karachi, Pakistan for isolation and storage of $C$. perfringens. The all isolated $C$. perfringens were further subjected to check their susceptibility and resistance pattern against Amoxicillin,

Trimethoprim/
Sulphamethaxzole and chloramphenicol by MIC (2-fold micro broth dilution method). The positive samples were selected for antimicrobial susceptibility testing through Micro Broth Dilution Method by using (MIC) method as described by the clinical laboratory standard institute (CLSI 2011). It has been observed that out of 100 samples (MIC; $\mu \mathrm{g} / \mathrm{ml}$ ) sensitivity and resistant of selected antibiotics against $C$. perfringens were: Amoxicillin sensitive 44 and 01 resistant, Chloramphenicol 43 sensitive and 02 resistant, and as for Trimethoprim/ Sulphamethaxzole 45 sesitive and 00 resistant (Table 3 ).

Table 3. Drugs sensitivity and resistant against Clostridium perfringens isolates from diarrheic goat

\begin{tabular}{|c|c|c|c|c|c|c|}
\hline \multirow{2}{*}{ Drugs } & \multicolumn{2}{|c|}{ *Positive } & \multicolumn{2}{c|}{ Sensitive } & \multicolumn{2}{c|}{ Resistant } \\
\cline { 2 - 7 } & Number & Percent & Number & Percent & Number & Percent \\
\hline Amoxicillin & 45 & 45.00 & 44 & 97.77 & 01 & 2.22 \\
\hline Chloramphenicol & 45 & 45.00 & 43 & 95.55 & 02 & 4.44 \\
\hline $\begin{array}{c}\text { Trimethoprim/ } \\
\text { Sulphamethaxzol } \\
\text { e }\end{array}$ & 45 & 45.00 & 45 & 100.00 & 00 & 0.00 \\
\hline
\end{tabular}

*positive number/percent calculated over total 100 number of collected sample

\section{Discussion}

Enterotoxemia is amongst the most important economic diseases [14], it is an infectious fatal disease of small ruminants caused by anaerobic gram positive bacterium $C$. perfringens [15]. This disease is one of the endemic disease in Pakistan that causes mortality up to 100 percent in goats [16]. We have investigated the occurrence of enterotoxaemia, 45 samples were found positive with $C$. perfringens from 100 faecal samples of diarrhoeic goats (Table 1). High prevalence of enterotoxaemia (45\%) was observed among diarrheic goats in the vicinity of district Tharparkar. Similarly, high prevalence of enterotoxaemia $(60 \%)$ was also reported from,15 samples found positive with $C$. perfringens out of 25 samples [17] and this high prevalence of enterotoxaemia was due to improper vaccination schedule against enterotoxaemia in the study area.
Previously reported that out of 100 faecal samples, $26 \%$ prevalence of $C$. perfringens was found among diarrheal goats [18]. Furthermore Taluka, $(27.38 \%)$ prevalence of enterotoxaemia in diseased goats were also observed in another study [19]. We have investigated Taluka wise enterotoxaemia among diarrhoeal goats in district Tharparkar, Sindh [18], as it was also previously reported study in goats in Khuzdar district Baluchistan. According to results Dahali had high prevalence of enterotoxaemia amongst the four Taluka and the reason behind this might be unawareness, lack of veterinary facilities or improper vaccination schedule $[20,21]$. The bacterial isolates of this study were confirmed by their typical growth pattern and colony characteristics, which include the double zone of hemolytic colonies of $C$. perfringens on blood agar. As previously reported that, $C$. perfringens produced smooth, large, regular convex 
and slightly opaque colonies and zone of complete hemolysis surrounded by wider zone of incomplete hemolysis [22, 23]. Dual zone of haemolysis created by $C$. Perfringens on the agar of sheep's blood $[24,25]$. Positive samples were selected for antimicrobial susceptibility testing through Micro Broth Dilution Method by using (MIC) method [26], Out of 45 isolates of $C$. perfringens only $01(2.22 \%)$ isolate was shown moderate level of resistant to amoxicillin phenotypically, as reported previously [27]. Furthermore, in another study investigated that all isolates were sensitive to amoxicillin from $100 C$. perfringens isolates [28]. Contra indicatory another study showed an excellent activity of amoxicillin against $C$. perfringens isolates [29].

2 out of 45 isolates of $C$. Perfringens with $(4.44 \%)$ were shown moderate level of resistant to Chloramphenicol phenotypically in our results. Previous research have indicated that $C$. perfringens isolates were sensitive to chloramphenicol only for few isolates [30]. However, Chloramphenicol experimentally showed an excellent activity against $C$. perfringens isolates [29]. In present study all isolates were sensitive

Trimethoprim/Sulphametahxzole from 45 isolates of $C$. Perfringens, as reported previously [28, 31].

\section{Conclusion}

It may be concluded that the $C$. perfringens was present in faecal samples of the diarrhoeic goats. A very high prevalence of enterotoxemia found in diarrhoeic goats in the vicinity of district Tharparkar, Sindh, Pakistan. Among three antimicrobials, Amoxicillin, Chloramphenicol and Trimethoprim/ Sulphamethaxzol, Trimethoprim/ Sulphamethaxzol were found more effective against $C$. perfringens followed by Amoxicillin and Chloramphenicol.

\section{Authors' contributions}

Conceived and designed the study: JK Zaman, MM Rahimoon \& A Babar,
Contributed to revise the manuscript: $\mathrm{AH}$ Mirani \& NH Kalhoro, Wrote the paper: JK Zaman, MM Rahimoon \& A Babar.

\section{Acknowledgement}

This work was supported by Sindh Poultry Vaccine centre Korangi Karachi Sindh, Pakistan for lab facilities.

\section{References}

1. Dubeuf J-P \& Boyazoglu J (2009). An international panorama of goat selection and breeds. Livestock Sci 120 (3): 225-231.

2. Luikart G, Fernández H, Mashkour M, England P, Taberlet P, Zeder M, Emshwiller E, Smith B, Bradley D (2006). Origins and diffusion of domestic goats inferred from DNA markers. Documenting domestication: New Genetic and Archaeological Paradigms: 294-305.

3. Chandran D, Naidu SS, Sugumar P, Rani GS, Vijayan SP, Mathur D, Garg LC, Srinivasan VA (2010). Development of a recombinant epsilon toxoid vaccine against enterotoxemia and its use as a combination vaccine with live attenuated sheep pox virus against enterotoxemia and sheep pox. Clin Vaccine Immunol 17(6): 10131016.

4. Jemal D, Shifa M, Kebede B (2016). Review on pulpy kidney disease. $J$ Vet Sci Technol 7(5): 361.

5. Uzal F, Vidal J, McClane B, Gurjar A (2010).Clostridium perfringens toxins involved in mammalian veterinary diseases. Open Toxinol J 2: 24.

6. Kiu R \& Hall LJ (2018). An update on the human and animal enteric pathogen Clostridium perfringens. Emerg Microbes Infect. 7(1): 1-15.

7. Kumar NV, Sreenivasulu D, Reddy Y(2014). Prevalence of Clostridium perfringens toxin genotypes in enterotoxemia suspected sheep flocks of Andhra Pradesh. Vet World 7(12): 1132-1136.

8. McClane BA (2003). Clostridium perfringens. In International 
Handbook of Foodborne Pathogens. CRC Press; 111-124.

9. Lewis C (2007). Clostridial diseases. Diseases of sheep. 4: 156-167.

10. Uzal FA, McClane BA, Cheung JK, Theoret J, Garcia JP, Moore RJ \& Rood JI (2015). Animal models to study the pathogenesis of human and animal Clostridium perfringens infections. Vet Microbiol 179(1-2): 23-33.

11. Martínez JL (2017). Effect of antibiotics on bacterial populations: a multi-hierachical selection process. F1000 Res 6: 51.

12. Brandt KK, Amézquita A, Backhaus $\mathrm{T}$, Boxall A, Coors A, Heberer T, Lawrence JR, Lazorchak J, Schönfeld J \& Snape JR (2015). Ecotoxicological assessment of antibiotics: a call for improved consideration of microorganisms. Environ Int 85: 189-205.

13. Fernández J, Bert F \& NicolasChanoine MH (2016). The challenges of multi-drug-resistance in hepatology. J of Hepatol 65(5): 10431054.

14. Hassanein KM, Sayed MM \& Hassan AM (2017). Pathological and biochemical studies on enterotoxemia in sheep. Comparative Clin Pathol 26 (3): 513-518.

15. Uzal FA \& Songer JG (2008). Diagnosis of Clostridium perfringens intestinal infections in sheep and goats. J Vet Diagn Invest 20(3): 253265.

16. Javed MT, Irfan M, Mukhtar N \& Hussain R (2009). An outbreak of enterotoxaemia at livestock farm during subtropical summer. Acta Tropica 112(2): 225-227.

17. Nazki S, Wani SA, Parveen R, Ahangar SA, Kashoo ZA, Hamid S, Dar ZA, Dar TA \& Dar PA (2017). Isolation, molecular characterization and prevalence of Clostridium perfringens in sheep and goats of
Kashmir Himalayas, India. Vet World 10(12): 1501.

18. Ajaz-ul-Haq, MKT, Taj I, Arif S, Ahmed A, Muhammad G, Ahmed Z, Ahmed Z, Abbas F \& Samad A (2016). Isolation of Clostridium perfringens from Goats and Sheep of the Khuzdar district of Balochistan, Pakistan. Int J Biosci 9(5): 156-162,

19. Singh DD (2017). Molecular pathogenesis of enterotoxaemia in neonatal goat kids. Indian $J$ Vet Pathol 41(4): 327-327.

20. Bozzola E, Bozzola M, Calcaterra V, Barberi S \& Villani A (2013). Infectious diseases and vaccination strategies: how to protect the "unprotectable"? ISRN Prev Med 2013: 765354.

21. Donadeu M, Nwankpa N, AbelaRidder B \& Dungu B (2019). Strategies to increase adoption of animal vaccines by smallholder farmers with focus on neglected diseases and marginalized populations. PLoS Neglected Tropical Dis 13(2): e0006989.

22. Karthik K, Manimaran K, Bharathi R, Shoba K (2017).Report of enterotoxaemia in goat kids. $A d v$ in Anim and Vet Sci 5: 289-292.

23. Pawaiya RS, Gururaj K, Gangwar NK, Singh DD, Kumar R \& Kumar $A(2020)$. The Challenges of Diagnosis and Control of Enterotoxaemia Caused by Clostridium perfringens in Small Ruminants. Adv Microbiol 10(5): 238-273.

24. Hall HE, Angelotti R, Lewis KH \& Foter MJ (1963). Characteristics of Clostridium perfringens strains associated with food and food-borne disease. J Bacteriol 85(5): 1094-1103.

25. Dar PS, Wani SA, Wani AH, Hussain I, Maqbool R, Ganaie MY, Kashoo ZA, Qureshi S (2017). Isolation, identification and molecular characterization of Clostridium perfringens from poultry in Kashmir 
valley, India. J Entomol Zool Stud 5(5): 409-414.

26. McLain JE, Cytryn E, Durso LM \& Young S (2016) Culture-based methods for detection of antibiotic resistance in agroecosystems: Advantages, challenges, and gaps in knowledge. J Environ Qual 45(2): 432-440.

27. El-Tayab WN \& Gomaa FAM (2012). Rapid Identification and Antimicrobial Susceptibility Profiling of Anaerobic Bacteria in Clinical Specimens. Egyptian J Med Microbiol 38(1230): 1-11.

28. Gad W, Hauck R, Krüger M \& Hafez $H$ (2011). Prevalence of Clostridium perfringens in commercial turkey and layer flocks. Arch Geflkd 75(2): 7479.
29. Llanco L, Nakano V, Ferreira A \& Avila-Campos M (2012). Toxinotyping and antimicrobial susceptibility of Clostridium perfringens isolated from broiler chickens with necrotic enteritis. Int $J$ Microbiol Res 4(7): 290.

30. Naidoo S, Perovic O, Richards G \& Duse A (2011). Clinically significant anaerobic bacteria isolated from patients in a South African academic hospital: Antimicrobial susceptibility testing. SAMJ: $S$ Afr Med J 101(10): 732-734.

31. Singh BR (2013). Antimicrobial sensitivity assay and antimicrobial chemotherapy in Animals: A Practical approach. Dis of Anim: Diag and Manag, BR Singh and $R$ Somvanshi. 